\title{
Optimization of Actinomycetes Changbai No.2 Liquid Fermentation by Response Surface Method
}

\author{
Ning YANG ${ }^{1}$, Yong WANG ${ }^{1, a^{*}}$, Yu-bo WANG ${ }^{2}$, Li ZHANG ${ }^{1}$, Yong LU ${ }^{1}$, Quan-jie \\ $\mathrm{CHEN}^{1}$, Wen-ge ZHANG ${ }^{3}$, Dan-hua SU ${ }^{4}$ and Ruo-peng LU ${ }^{4}$ \\ 1 University of Science and Technology Liaoning, Anshan 114051 P. R.China \\ 2 Shenyang Agricultural University, Shenyang, 110161 P. R. China \\ ${ }^{3}$ Anshan Normal University Affiliated Medical School, Anshan, 114001 P. R. China \\ ${ }^{4}$ Qianshan Datun Town Agricultural Technology Extension Station, Anshan 114000 P. R.China \\ awy2002866@126.com \\ ${ }^{*}$ Corresponding author
}

Keywords: Fermentation optimization; Media component; Culture conditions

Abstract. Actinomycetes are affected by external conditions during fermentation, especially the secondary metabolites, the influence of the external conditions is very large. In order to produce the most abundant pigment, the method of response surface was used to optimize the liquid fermentation condition of the actinomycetes Changbai No.2. A single factor was used to determine the best single factor, and the Plackett-Burman experiment was used, and statistical software SPSS 17.0 for statistical processing, there are three main influencing factors: the concentration of starch, fermentation time and temperature. Finally, using Box - Behnken design to get the best value of these three factors is: the concentration of starch is $18.42 \mathrm{~g} / \mathrm{L}$, fermentation time is 6.46 days, the temperature is $26.19^{\circ} \mathrm{C}$. Postoptimality, the absorbance of the Changbai No. 2 fermentation liquid was 2.098 .

\section{Introduction}

Microbial pigment is a natural pigment, it's extracted from microorganisms, not limited by resources, time, and space, unparalleled advantages of plant pigments and animal pigments.[1] Microbial fermentation is used to produce a variety of pigments. [2] The pigment is the secondary metabolite of actinomycetes, and the production of secondary metabolites will be affected by different cultivation conditions. Therefore, the optimization of culture medium and fermentation conditions of actinomycetes is a very important part of industrial production, which is an indispensable link from laboratory to industrial production. [3]

Response surface methodogy(RSM)has been widely used in the optimization of fermentation culture medium, optimization of culture conditions and enzymatic hydrolysis and other biochemical reaction optimization and model establishment. [4,5] In this experiment, Plackett-Burman experiment and Box-Behnken experiment were used to optimize the composition of fermentation medium to improve the yield of secondary metabolites pigment of actinomyces. [6,7]

\section{Materials and methods}

\section{Materials}

\section{Bacterial strain}

Tested strain: Actinomycetes strain Changbai No.2 (separation, screening and preservation from the soil of Changbai mountain).

\section{Culture medium}

Liquid fermentation medium: Gause's No.1 liquid medium. 


\section{methods}

\section{Single-factor experiment}

Single factor test was used to optimize the fermentation process parameters such as culture medium, fermentation temperature, fermentation time, liquid loading quantity, inoculation quantity and $\mathrm{pH}$ value. Each time three parallel experiments were conducted, the average was averaged. The fermentation liquid was centrifuged for $30 \mathrm{~min}$ under the condition of $4000 \mathrm{r} / \mathrm{min}$. The lower cell body was then placed in the mortar, and the quartz sand and a small amount of fermentation liquid were added to grind, and then the centrifuge was used after $20 \mathrm{~min}$. The absorbance at $527 \mathrm{~nm}$ was determined by mixing the supernatant liquid with the upper cleaning liquid after the first centrifuge. Then determine the best condition for optimal single factor.

\section{Design experiment of response Surface Placket-Burman (P-B). [8]}

Selected on the basis of single factor experiment, effect on fermentation of larger factors to optimize experiment, these factors are: starch, potassium nitrate, culture temperature, $\mathrm{pH}$ value, fermentation time and fluid volume. Using P-B program test, the absorbance of pigment in the fermentation liquid was used as the evaluation index, and three parallel experiments were performed in each group, and the average value was taken at the time of measurement. It is concluded that the above factors have the most influence on the production of the actinomycetes Changbai No.2. The six main factors that will affect the fermentation of actinomycetes Changbai No.2 are the main components of P-B design. First of all, the high level of (1) and the low level (-1) are set, in which the maximum data is 1.25 times the minimum data, with absorbance as the response value $\mathrm{Y}$. P-B design experiment was shown in Table 1.1. The data were statistically processed using SPSS 17.0 software, and the obtained data was analyzed with a single factor variance, and the difference was significant with $\mathrm{P}<0.05$. Select 3 significant factors that affect the absorbency.

Tab.1.1 Fermentation conditions for screening Plackett-Burman experimental design factors and levels

\begin{tabular}{|c|c|c|c|c|}
\hline $\begin{array}{l}\text { Experimental } \\
\text { factor }\end{array}$ & Unit & code & (-) low level & $(+)$ high level \\
\hline starch & $\mathrm{g} / \mathrm{L}$ & $\mathrm{X} 1$ & 18 & 22.5 \\
\hline $\begin{array}{l}\text { nitrate of } \\
\text { potash }\end{array}$ & $\mathrm{g} / \mathrm{L}$ & $\mathrm{X} 2$ & 0.9 & 1.1 \\
\hline $\begin{array}{l}\text { the volume of } \\
\text { liquid }\end{array}$ & $\mathrm{mL}$ & X7 & 80 & 100 \\
\hline $\begin{array}{l}\text { fermentation } \\
\text { time }\end{array}$ & d & $\mathrm{X} 8$ & 5.5 & 7 \\
\hline temperature & ${ }^{\circ} \mathrm{C}$ & X9 & 24 & 30 \\
\hline $\mathrm{pH}$ & - & $\mathrm{X} 11$ & 6 & 7.5 \\
\hline
\end{tabular}

\section{Box-Behnken (B-B) experimental design}

According to the conclusion of $\mathrm{P}-\mathrm{B}$, the optimum value of selected factors was determined by software B-B experiment design.

\section{Model verification test}

In order to further verify the predictive value of response surface method, the best predicted value after optimization was fermented, and each experiment was set up with 3 repetitions, and the average value was obtained. By comparing the experimental values with the predicted values, we can determine whether the optimal fermentation conditions obtained by the response surface method are accurate and reliable, and whether they are of practical value. 


\section{Results and analysis}

\section{Results and analysis of Placket-Burman test}

In the 12 experiments designed by Design-Expert.V.8.0.6 software, the experiment was carried out according to the combination of experimental components and experimental conditions designed in table 2.1, and three parallel tests were designed for each group. Then according to the experiments, the experimental conditions for training, training is completed, according to the treatment method of fermented liquid fermented liquid before, and then determine the absorbance of fermented liquid, after processing will be parallel to the three groups of experiments take its average.

Tab.2.1 Experimental design and result of Plackett-Burman

\begin{tabular}{cccccccc}
\hline component & $\begin{array}{c}\text { Starch } \\
\mathrm{g} / \mathrm{L}\end{array}$ & $\begin{array}{c}\text { Potassium } \\
\text { nitrate } \\
\mathrm{g} / \mathrm{L}\end{array}$ & $\begin{array}{c}\text { Fermentation } \\
\text { time } \\
\mathrm{d}\end{array}$ & $\begin{array}{c}\text { Culture } \\
\text { temperature } \\
{ }^{\circ} \mathrm{C}\end{array}$ & $\mathrm{pH}$ & $\begin{array}{c}\text { With } \\
\text { fluid } \\
\text { volume } \\
\mathrm{mL}\end{array}$ & Absorbance \\
\hline 1 & -1.00 & -1.00 & -1.00 & 1.00 & -1.00 & 1.00 & 1.933 \\
2 & 1.00 & 1.00 & -1.00 & 1.00 & 1.00 & 1.00 & 2.400 \\
3 & 1.00 & -1.00 & 1.00 & 1.00 & 1.00 & -1.00 & 1.933 \\
4 & -1.00 & -1.00 & -1.00 & -1.00 & -1.00 & -1.00 & 1.633 \\
5 & -1.00 & 1.00 & -1.00 & 1.00 & 1.00 & -1.00 & 2.00 \\
6 & -1.00 & -1.00 & 1.00 & -1.00 & 1.00 & 1.00 & 1.533 \\
7 & -1.00 & 1.00 & 1.00 & 1.00 & -1.00 & -1.00 & 1.667 \\
8 & -1.00 & 1.00 & 1.00 & -1.00 & 1.00 & 1.00 & 1.633 \\
9 & 1.00 & 1.00 & 1.00 & -1.00 & -1.00 & -1.00 & 1.933 \\
10 & 1.00 & -1.00 & 1.00 & 1.00 & -1.00 & 1.00 & 1.967 \\
11 & 1.00 & -1.00 & -1.00 & -1.00 & 1.00 & -1.00 & 1.800 \\
12 & 1.00 & 1.00 & -1.00 & -1.00 & -1.00 & 1.00 & 1.967 \\
\hline
\end{tabular}

According to the data obtained in the software Placket-Burman table, the data is processed by the statistical software SPSS 17.0, which can be used to establish a model. The specific data is shown in table 2.2 below, three distinct items can be drawn from the chart, because the effect of $\operatorname{Pr}<0.05$ is significant, the impact of $\operatorname{Pr}<0.01$ is significant. And because $\mathrm{P}(\mathrm{X} 1)=0.005, \mathrm{P}(\mathrm{X} 3)=0.013$, $\mathrm{P}(\mathrm{X} 4)=0.011$, therefore $\mathrm{X} 1 、 \mathrm{X} 3 、 \mathrm{X} 4$ that is the significant term in this model. Starch, fermentation time and culture temperature were used as three significant factors influencing fermentation culture. The three significant items were further optimized by the experimental design of the response surface.

Tab.2.2 The significant of factors

\begin{tabular}{cccccc}
\hline \multirow{2}{*}{ model } & \multicolumn{2}{c}{$\begin{array}{c}\text { Non-standardized } \\
\text { coefficient }\end{array}$} & $\begin{array}{c}\text { The standard } \\
\text { coefficient }\end{array}$ & $\mathrm{t}$ & $\operatorname{Pr}>|\mathrm{t}|$ \\
\cline { 2 - 5 } & $\mathrm{B}$ & Standard error & A trial version & & 0.005 \\
$\begin{array}{c}\text { Starch } \\
\text { Potassium } \\
\text { nitrate }\end{array}$ & 0.125 & 0.27 & 0.584 & 4.679 & 0.081 \\
$\begin{array}{c}\text { Fermentation } \\
\text { time }\end{array}$ & 0.058 & 0.27 & 0.273 & 2.185 & 0.013 \\
$\begin{array}{c}\text { Culture } \\
\text { temperature } \\
\text { pH }\end{array}$ & -0.100 & 0.27 & -0.468 & -3.744 & 0.011 \\
$\begin{array}{c}\text { With fluid } \\
\text { volume }\end{array}$ & 0.106 & 0.27 & 0.496 & 3.968 & 0.224 \\
\hline
\end{tabular}


Tab.2.3 Regression analysis of variance table

\begin{tabular}{cccccc}
\hline model & $\begin{array}{c}\text { Sum of } \\
\text { squares }\end{array}$ & df & $\begin{array}{c}\text { The mean } \\
\text { square }\end{array}$ & Value of $F$ & significant \\
\hline Regression & 0.507 & 6 & 0.085 & 9.854 & $0.12^{\mathrm{a}}$ \\
Residual error & 0.043 & 5 & 0.009 & & \\
Total & 0.550 & 11 & & & \\
\hline
\end{tabular}

a. prediction variables: (constants), With fluid volume,pH,Culture temperature,Fermentation time,Potassium nitrate,starch .

Tab.2.4 Model summary

\begin{tabular}{ccccc}
\hline model & $\mathrm{R}$ & $\mathrm{R}^{2}$ & Adjust $\mathrm{R}^{2}$ & $\begin{array}{c}\text { Standard } \\
\text { estimation error }\end{array}$ \\
\hline 1 & $0.960^{\mathrm{a}}$ & 0.922 & 0.828 & 0.9260 \\
\hline
\end{tabular}

a. prediction variables: (constants), With fluid volume, $\mathrm{pH}$, Culture temperature,Fermentation time,Potassium nitrate,starch .

\section{Analysis of the results of response surface Box-Behnken experiment}

The 3 significant items obtained by the Placket-Burman test were the influencing factors of this experiment, other culture medium formulations and culture conditions remain unchanged, according to the response surface software Box-Behnken designed the experimental scheme, then a series of experiments were carried out using the experiment, the fermentation fluid was fermentated according to the experimental scheme, and the results of the experiment were averaged by three parallel experiments. After culture, the fermentation liquid was treated accordingly, and the absorbance was determined at the wavelength of $527 \mathrm{~nm}$. Finally, the results of the experiment are obtained, as shown in table 2.5 and 2.6 :

Tab.2.5 Box-Behnken experimental results analysis

\begin{tabular}{ccccc}
\hline Run & A starch $(\mathrm{g} / \mathrm{L})$ & $\begin{array}{c}\text { B Fermentation } \\
\text { time }(\mathrm{d})\end{array}$ & $\begin{array}{c}\text { C Culture } \\
\text { temperature }\left({ }^{\circ} \mathrm{C}\right)\end{array}$ & $\begin{array}{c}\text { Y } \\
\text { absorbance }\end{array}$ \\
\hline 1 & 20.00 & 8.00 & 20.85 & 2.003 \\
2 & 20.00 & 6.40 & 27.80 & 2.23 \\
3 & 15.00 & 6.40 & 20.85 & 2.067 \\
4 & 15.00 & 4.80 & 27.80 & 2.02 \\
5 & 20.00 & 6.40 & 27.80 & 2.197 \\
6 & 20.00 & 4.80 & 20.85 & 2.25 \\
7 & 20.00 & 6.40 & 27.80 & 2.23 \\
8 & 25.00 & 8.00 & 27.80 & 1.7 \\
9 & 20.00 & 6.40 & 27.80 & 2.25 \\
10 & 20.00 & 6.40 & 27.80 & 2.167 \\
11 & 15.00 & 6.40 & 34.75 & 2.033 \\
12 & 25.00 & 4.80 & 27.80 & 1.8 \\
13 & 20.00 & 8.00 & 34.75 & 1.933 \\
14 & 25.00 & 6.40 & 34.75 & 1.833 \\
15 & 25.00 & 6.40 & 20.85 & 1.867 \\
16 & 20.00 & 4.80 & 34.75 & 2.1 \\
17 & 15.00 & 8.00 & 27.80 & 1.967 \\
\hline
\end{tabular}


Tab.2.6 Analysis of experimental results of Box-Behnken

\begin{tabular}{cccccc}
\hline $\begin{array}{c}\text { Sources of } \\
\text { variance }\end{array}$ & $\begin{array}{c}\text { Sum of } \\
\text { squares }\end{array}$ & $\begin{array}{c}\text { Degree of } \\
\text { freedom }\end{array}$ & $\begin{array}{c}\text { The mean } \\
\text { square }\end{array}$ & Value of $\mathrm{F}$ & Pr>F \\
\hline model & 0.45 & 9 & 0.050 & 21.18 & 0.0003 significant \\
A-starch & 0.098 & 1 & 0.098 & 41.34 & 0.0004 \\
$\begin{array}{c}\text { B-Fermentation } \\
\text { time }\end{array}$ & 0.04 & 1 & 0.040 & 16.89 & 0.0045 \\
$\begin{array}{c}\text { C-Incubation } \\
\text { temperature }\end{array}$ & 0.01 & 1 & 0.010 & 4.36 & 0.0752 \\
AB & 0.000 & 1 & 0.000 & 0.23 & 0.6446 \\
AC & 0.000 & 1 & 0.000 & 0.000 & 1.0000 \\
BC & 0.002 & 1 & 0.002 & 0.67 & 0.4392 \\
$\mathrm{~A}^{2}$ & 0.23 & 1 & 0.23 & 95.49 & 0.0001 \\
$\mathrm{~B}^{2}$ & 0.052 & 1 & 0.052 & 21.72 & 0.2135 \\
$\mathrm{C}^{2}$ & 0.004 & 1 & 0.004 & 1.87 & - \\
Residual item & 0.017 & 7 & 0.002 & - & - \\
Loss of quasi item & 0.012 & 3 & 0.004 & 3.83 & 0.1138 not significant \\
error & 0.004 & 4 & 0.001 & - & - \\
Sum & 0.47 & 16 & - & - & - \\
\hline
\end{tabular}

\section{Verification test of the model}

It can be seen from the above table that the Pr of the model is 0.003 and $\operatorname{Pr}<0.01$, so it's remarkable, its misfit is 0.1138 , misfit $>0.05$, it is not obvious that the model is missing. The $\mathrm{R}^{2}$ of the complex correlation coefficients of the model is 0.9646 , it is good to show the fitting of the data between the experiment and the actual measurement; The adjusted R2 is 0.190 , its numerical change is related to starch concentration, fermentation time and culture temperature; The variation coefficient C.V can represent the accuracy of the model, the smaller the C.V, the more accurate it is, in this experiment, $\mathrm{C} . \mathrm{V}=2.39 \%$, indicates that the operation accuracy of the experiment is relatively high.

The regression equation was obtained by using the experimental data of the software design-expert. V.8.0.6: Absorbance $=2.12-0.11 \mathrm{~A}-0.071 \mathrm{~B}-0.036 \mathrm{C}-0.012 \mathrm{AB}+0.000 \mathrm{AC}+0.020 \mathrm{BC}-0.23 \mathrm{~A}^{2}$

$$
-0.11 B^{2}-0.033 C^{2} \text {. }
$$

A partial derivative of this equation for different independent variables, the following equations can be obtained

$$
\begin{gathered}
0.11+0.012 \mathrm{~B}+0.46 \mathrm{~A}=0 \\
0.071+0.012 \mathrm{~A}-0.02 \mathrm{C}+0.22 \mathrm{~B}=0 \\
0.036-0.02 \mathrm{~B}+0.066 \mathrm{C}=0
\end{gathered}
$$

Through this system, $\mathrm{A}=-0.25, \mathrm{~B}=0.38, \mathrm{C}=-0.43$, the actual value of each factor can be obtained by conversion: the concentration of starch is $18.42 \mathrm{~g} / \mathrm{L}$, the fermentation time was 6.46 days, temperature is $26.19^{\circ} \mathrm{C}$.

Response surface analysis diagram by software Design-Expert.V. 8.0.6:
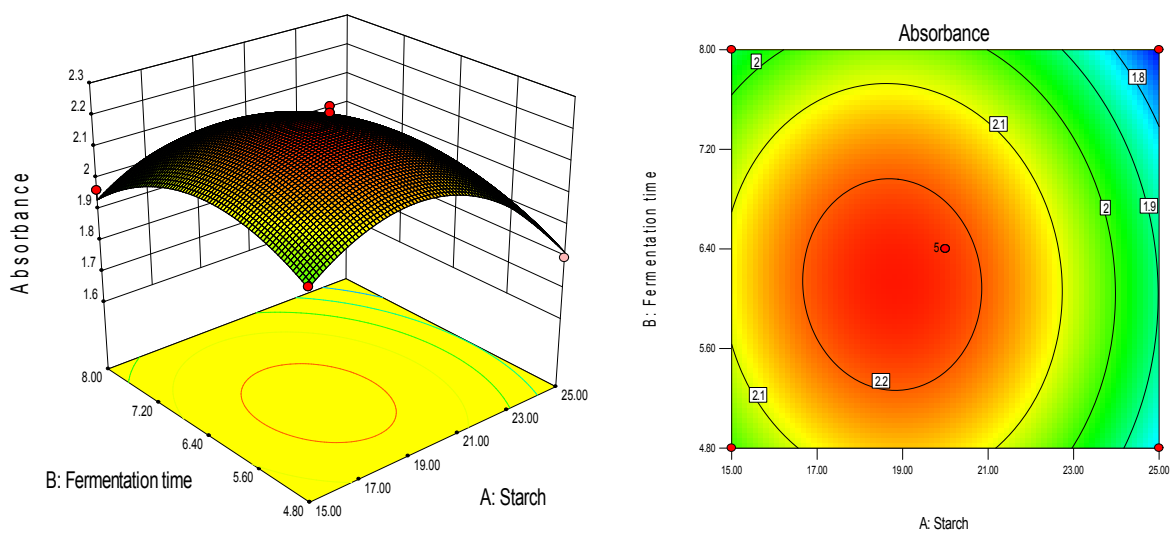

Fig.2.1 Starch and fermentation time effect on the pigmentof response surface and contour plots 

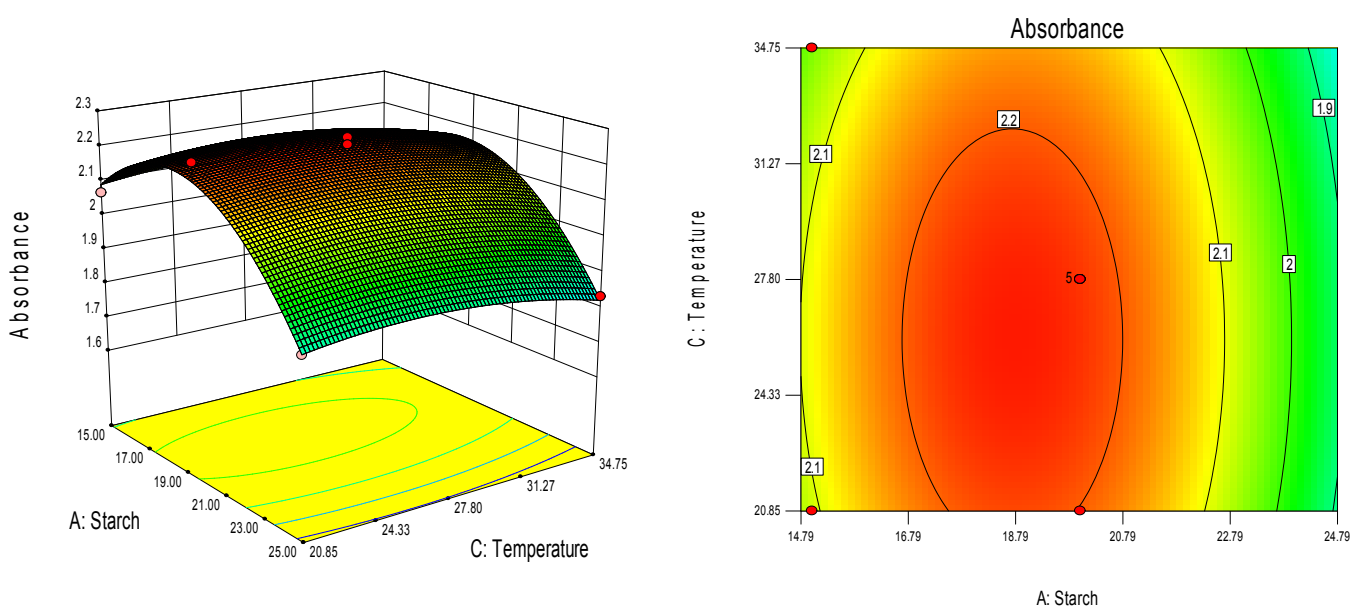

Fig.2.2 Starch and culture temperature effects on the pigment response surface and contour plots
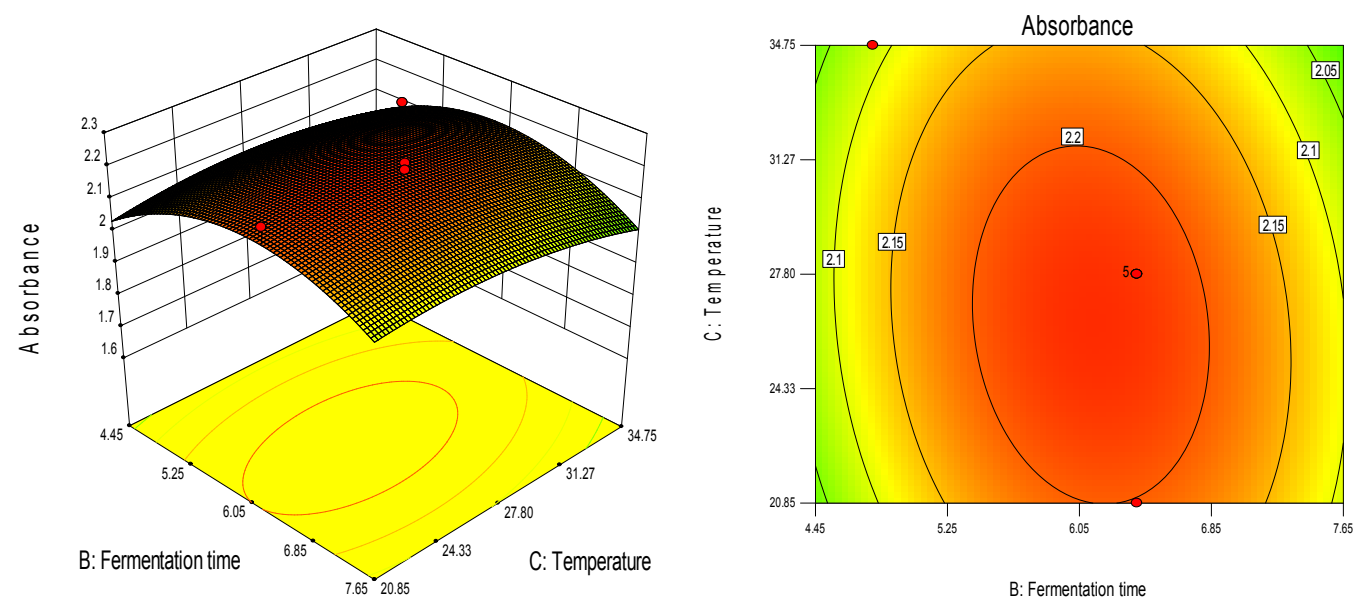

Fig.2.3 Culture temperature and fermentation time effects on the pigment diameter response surface and contour plots

Response surface figure is the graphical expression of the regression equation, as can be seen from the response surface analysis, the size of the absorbance value $\mathrm{Y}$ is increased with the increase of the values of two factors, first reduce the trend, after various interaction factor has a best combination to maximize the $\mathrm{Y}$ value. According to the regression equation of Design-Expert.V.8.0.6 software, the best predictive value is: The concentration of starch is $18.42 \mathrm{~g} / \mathrm{L}$, the fermentation time was 6.46 days, Temperature is $26.19^{\circ} \mathrm{C}$, the absorbance is calculated at 2.098 , then the actual absorbance is 2.1 , which can be obtained by repeated experiments. The difference between the two values is small, and the error is small.

\section{Conclusion}

Single factor optimization experiment results show: The factors that influence the fermentation liquid are starch, potassium nitrate, culture temperature, acid alkalinity, fermentation time and liquid loading.

On the basis of single factor experiment, using the response surface method on the metabolism of actinomycetes long white 2 pigment, the optimization of fermentation conditions, established the fermented liquid of pigment content and starch concentration in the culture medium, fermentation time and temperature of three factors quadratic polynomial regression model, and verified experiment proves that the model is reasonable and reliable.

The optimal culture conditions for the determination of actinomycetes Changbai No.2 metabolism were: The concentration of starch is $18.42 \mathrm{~g} / \mathrm{L}$, The fermentation time was 6.46 days, temperature is $26.19{ }^{\circ} \mathrm{C}$. In this condition, the absorbance of pigment in the actinomycete Changbai No. 2 
fermentation liquid was calculated as 2.098 , and the actual absorbance obtained by repeated experiments was 2.1. The experimental results show that the model is basically consistent with the test results, and the model can predict $Y$ values reasonably and effectively, which lays the foundation for industrial production.

\section{Reference:}

[1] Moselio S. Encyclopedia of Microbiology(Third Edition)[M].San Diego Calif: Academic Press, 2009.457-471.

[2] Palanivel V, Seralathan K K, Vellingiri B.et al. Natural pigment extraction from five filamentous fungi for industrial applications and dyeing of leather[J]. Carbohydrate Polymers, 2010, 79(2):262-268.

[3] Zhi-kai DAI, Cui ZHANG, Zheng RUAN. Experiment design and optimization and its application in fermentation medium optimization[J]. Microbiology bulletin, 2010, 37(6): 894-903. 。 [4] Guo-ying LV, Zuo-fa ZHANG, Hui-juan PAN, et al. Response surface analysis was used to optimize the fermentation medium of mushroom polysaccharide[J].Journal of fungus, 2010, 29(1):106-112.

[5] Yun-xiang WANG, Feng-xia LV, Zhao-xin LU. Study on the response surface method of parasol fermentation medium [J]. Journal of nanjing agricultural university, 2004, 27(3):89-94.

[6] Trupkin S, Levin S, Forchiassin F. Optimization of a culture medium for lig-ninolytic enzyme production and synthetic dye decolorization using response surface methodology[J]. Ind Microbiol Biotechnol, 2003, 30(12): 682-690.

[7] Huai-qiu XIAO, Yu-zhen LI. The response surface optimization of the extraction process of total flavonoids from sea sands [J]. Amino acids and biological resources, 2010, 34(8): 68-72.

[8] Ming YANG. Minitab is used for center compound design and data processing [J]. Pharmaceutical services and research, 2007, 7(3): 231-234. 